\title{
Intelligent and Cognitive Technologies in Education of International Economic Relations Students and Human Resource Development: Methodology in Language Teaching and Distance Learning
}

\author{
By Nayden Nenkov ${ }^{1}$, Yuriy Dyachenko ${ }^{2}$, Mariana Petrova ${ }^{3}$, Galyna Bondarenko ${ }^{4}$, \\ Valeriia Pustovit ${ }^{5}$
}

\begin{abstract}
This study is aimed at ensuring quality education and promoting lifelong learning opportunities we need for empowering learning. This paper attempts to consider the possibility and unite the conditions for intelligent and cognitive technologies application to human resource development and education of students. There is proposed Actor-Network Theory as a theoretical framework for managing actors of educational process as human and non-human agent interactions. As a core of interactions we use Facebook social infrastructure which is a tool to build the global community. We consider artificial technologies and distance learning in education, cognitive technologies for human resource development, especially for internally displaced persons in Ukraine. As a hub for this technologies we use chatbot based on natural language processing wit.ai technologies. Intelligent and cognitive technologies provide the opportunities to incorporate cognitive characteristics of each student with a view to address individual approach for students. We developed the curriculum "International economic relations" based on relevant stakeholders' requests with regard to intelligent and cognitive technologies. In future it can yield the most suitable solution for knowledge transfer from one agent to another in order to ensure inclusive and equitable quality education.
\end{abstract}

\section{Keywords: Intelligent and Cognitive Technologies, Human Resource Development, International Economic Relations, Methodology in Language Teaching}

\section{Framework}

Due to Sustainable Development Goal 4, we have to "ensure inclusive and equitable quality education and promote lifelong learning opportunities for all" (UN, 2015). In order to support it we need to empower learning with technologies which assist people in managing teaching and learning. In this frames we consider the possibility and conditions of application of intelligent and cognitive technologies to education of students and human resource development. We must involve basics of human intelligent behaviour to deal with this.

One of the most general approaches to describe it is Luhmann's System Theory. In

Professor in Computer system and Technologies, Faculty of Mathematics and Computer Science, Konstantin Preslavsky University of Shumen (Bulgaria).

${ }^{2} \mathrm{Head}$ of Department of International Economic Relations, Volodymyr Dahl East Ukrainian National University (Ukraine).

${ }^{3}$ Director of Education Technologies Center, St. Cyril and St. Methodius University of Veliko Turnovo (Bulgaria), Professor of Department of Management, ISMA University (Latvia).

${ }^{4}$ Head of Department of Ukrainian Philology and Journalism, Volodymyr Dahl East Ukrainian National University (Ukraine).

5Professor of Department of Ukrainian Philology and Journalism, Volodymyr Dahl East Ukrainian National University (Ukraine). 
Luhmann's opinion distinguishing the system and the environment (Luhmann, 1992) and their contradictions are central in the existence of autopoietic systems because they survive as the unities of contradictions they mastered (Bausch, 2001). In their reproduction, systems find their boundaries in basal self-reference; they proceed to reflexivity as communication about communication; and then to reflections when they recognize their separations from their environments (Bausch, 2001). Accordingly, mandatory abilities of intelligence are self-awareness as a form of internal feedback and communication as a form of interaction with external environment by means of information.

Luhmann considers that emergency of behaviour of contingent systems has been achieved through interaction: "communication is the elemental unit of self-constitution; action is the elemental unit of social system self-observation and self-description" (Luhmann, 1995). Also Parsons stated: "There is a double contingency inherent in interaction. On the one hand, ego's gratifications are contingent in his selection among available alternatives. But in turn, altered reaction will be contingent on ego's selection and will result from a complementary selection of the altered part. Because of these double contingency, communication, which is the preoccupation of cultural patterns, could not exist without both generalization from the particularity of the specific situations (which are never identical for ego and alteration) and stability in meaning which can only be assured by "conventions" observed by both parties» (Parsons \& Shils, 1951). As a basis for managing human-non-human communications we propose ActorNetwork Theory (ANT).

Communication in general refers to humans, institutions and non-humans (particularly, intelligent systems) as its actors are involved into interactions. Law describes ANT as “...a disparate family of material-semiotic tools, sensibilities and methods of analysis that treat everything in the social and natural worlds as a continuously generated effect of the webs of relations within which they are located. It assumes that nothing has reality or form outside the enactment of those relations. Its studies explore and characterise the webs and the practices that carry them" (Law, 2009). According to Latour, "ANT states that if we wish to be a bit more realistic about social ties than "reasonable" sociologists, then we have to accept that the continuity of any course of action will rarely consist of human-to human connections (for which the basic social skills would be enough anyway) or of object-object connections, but they will probably zigzag from one to another." (Latour, 2005).

Consequently, actor in ANT is "anything that does modify the state of affairs by making a difference" (Latour, 2005). But that does not mean equating of humans and nonhumans: "we have to take non-humans into account only as long as they are rendered commensurable with social ties and also to accept, an instant later, their fundamental incommensurability" (Latour, 2005). Latour defines network as "a concept, not a thing out there" (Latour, 2005) and as "a string of actions where each participant is treated as a full-blown mediator" (Latour, 2005). Respectively, "mediators transform, translate, distort, and modify the meaning or the elements they are supposed to carry" (Latour, 2005). ANT based on three methodological principles: "The first is agnosticism, which advocates abandoning any a priori assumptions of the nature of networks, causal conditions, or the accuracy of actant's accounts... The second principle is generalized 
symmetry, employing a single explanatory frame when interpreting actants, human and non-human... The third is free association, which advocates abandoning any distinction between natural and social phenomenon" (Crawford, 2005). ANT enables us to analyse interactions between human actors with intelligence and non-human actors without intelligence. But developing of science and engineering makes us consider the possibility of non-human actors with intelligence that could be developed under approach of cognitive sciences as interdisciplinary study of mind and intelligence, embracing philosophy, psychology, artificial intelligence, neuroscience, linguistics and anthropology. One of approaches to the description of cognition activities lies in the creation of models of the reality within education in particular.

\section{Description of Practical Application}

Education in the field of International Economic Relations in the modern age strikes some challenges such as high competitiveness, growing risks, lack of predictability. Management of education as a service is a process aiming to improve the structure of providers of educational services and educational structure of society. For construction of this structures we need to consider some actions relating to some system. Setting such actions leads to a type of management through setting the strategy and coordinating the efforts. In order to achieve the objectives we need to consider a kind of predictability of the system. But due to the unpredictability of intelligence behaviour we will face uncertainty in the future. Thus, these actions, even in frames of cultural and economic institutions, make it impossible to build a closed system that intends to give an opportunity to obtain pre-defined results of intelligence activity (including the artificial one) which becomes a source of instability and potential danger. Practically we try to foresee any future changes at the workplace to deliver the knowledge to students. In Volodymyr Dahl East Ukrainian National University in the curricula of Master's studies - course of "International economic relations", one of the related steps we support the intelligent and cognitive technologies with the following courses: "Information management", "Intelligent technologies in corporate governance", "Innovative development of enterprise and the knowledge economy", "Cognitive Technologies in Economics".

The fast growth of the distance education branch activates old questions without answers as well as produces a wide range of new problems at accelerated rates. The information-communicational globalization for its part increases the need of creating science-grounded strategy for development of the distance education. A prior object of this strategy should be the support of high quality on all educational stages. The need of creating private and shared standards for distance education is objectified (Petrova, 2007). One of the projections of the new quality of education is that education should challenge and bring to the front the personal cognitive activity of the student. It should be present in the selection of education content, in the choice of the purposes, the methods for work and the behavior (Petrova \& Petrov, 2002).

Learning management systems today enable us to break the space-time linking between a teacher and a student. Modern learning management system is based on different elearning platforms. One of the most common ones is Moodle as a free and open-source 
software learning management system which is used to create private websites with online courses for educators and trainees to achieve learning goals.

In Shumen University the distance-learning platform is used based on Moodle (Nenkov, 2015). The teaching materials are in the form of lectures, promoting discussions. For verification of the knowledge gained by the students, tests and analysis of the results are performed (Nenkov, 2015). The reason for this is that the arrangement of education in Bulgaria moves more or less towards the strenuous course of the development and application of its own or established in practice new learning technologies. Parts of this course are the attempts to develop the intra-school information and communication networks; conducting experiments inside these networks for upgrading the traditional information technologies for education or maintenance and reviving of the classical learning process. The capacity for innovation experiments and wide-ranging psychopedagogical and didactic-methodical understanding are considerably wider than the need for development and launching new information technologies in the education provided by introducing the corporate school network into the global information and communication network. With the transition into this entirely new level the objectively necessary conditions are created for the application of the simplest organization and technical decisions to introduce the elements of distance learning in the traditional learning process. (Petrova, 2007).

Considering the requirements of Artificial Intelligence agents which represent the mediation between the students and the learning management system as two main intelligence activities of teachers, which can be replaced by Artificial Intelligence agent, in our opinion, they are the creation of learning materials and verification of the students' knowledge. The solution of the first task means automation of the development of the content for online courses by filtration of unstructured sources into lectures and exercises. The second task is conducting a dialogue creating tasks for students; evaluation of answers and assessment of level of the students' knowledge.

When viewed from the automation perspective, the following problems are evidenced: a dialog in natural language, natural language classifier and text analysis. Relevance of the information technologies use in language teaching is primarily dictated by the needs to improve the efficiency of learning, developing, in particular, the need of the independent learning skills, research, creative approach to learning, the formation of critical thinking, the new culture. The use of intelligent and cognitive technologies in the language teaching, including the state language, are not only due to the desire for novelty, this study allows realizing personally oriented approach, which is the main focus of the conceptual formation of the XXI century (Pustovit et al., 2013).

Formation of professional communicative competence of economics students by means of distance education implemented by means of learning management system Moodle (Bondarenko, 2014). The use of intelligent and cognitive technologies can be integrated with audiovisual information presented in the form of animation, video film, slides, text and graphic information through interactive dialogue. If a group of students works simultaneously with all of them, the information is absorbed much faster and with interest. In addition, students learn all aspects of language: phonetics, vocabulary, grammar and communication.

Thus, the greatest advantage of the intelligent and cognitive technologies is the ability to 
provide an individual approach to students giving them the opportunity to learn the language at an individual pace and sequence that takes into account the psychological characteristics of each student, which greatly improves the quality of mastering the linguistic material. The personalization of information has a great influence on the Human Resource function and improves the employee development (Artificial Intelligence Enables Proficiency, 2017):

- Artificial intelligence integrated into education systems suggests some relevant training that is based on the analysis and statistics according to the employee's level;

- each team member in your organization will get a personal coach to learn and perform better;

- add machine learning capabilities to Human Resource systems to develop your talents and improve employee management strategies:

- Artificial intelligence may handle new employment routine questions about the company;

- Artificial intelligence systems will suggest development programs and external events for better performance as well.

Artificial intelligence technologies enable the prompt analysis (cleaning, investigating and making conclusions) of data by people that do not have special skills in data analysis. The most difficult task in Human Resource Development (Buzko, 2012) is to determine the effectiveness of training costs due to its branching and sophisticated feedback caused by improved production results of staff who took part in it. The aim of the Human Resource Development system is to make the knowledge, skills and experience of the staff correspond to the desired indices at different levels: enterprise strategy, branch activity, work duties. The specification of employees who need this training, its content and duration is the supposition of the effective work of Human Resource Development system. The period during which learning outcomes have an impact on the performance of the company depends on many external factors regarding the company. Considering that the disclosure of financial opportunities for training and implementation of training going on for some time, changes in the financial situation of the enterprise affecting some delay on parameters that characterize training.

As a core of interaction between actors (students, teachers, bots) and functions (learning management, teachers assistance, informing) empowered by intelligent and cognitive technologies we proposed Facebook social infrastructure as the most visited communication environment in Internet (overall 1,68 bln. monthly active Facebook users by the June 2016) with highest penetration in Europe (51,5\% of Internet users in EU are Facebook subscribers in June 2016). Now Facebook positions itself as an instrument to build global community: "Connecting everyone to the internet is also necessary for building an informed community. For the majority of people around the world, the debate is not about the quality of public discourse but whether they have access to basic information they need at all, often related to health, education and jobs... Facebook is a work in progress, and we are dedicated to learning and improving" (Zuckerberg, 2017).

Modern policy of this social network enables creating autonomous (in a various degree) bots to automate interactions between users. Facebook in April 2016 extended its achievement beyond online socialising by building artificial-intelligence powered bots into 
its Messenger application to allow users to have software engagement in lifelike text exchanges. Availability of Wit.ai's Bot Engine will enable developers to build more complex bots that can interpret the intent from natural language, and continuously learn to get better over time (Marcus, 2016). Unlike previous generations of bots this one is more intelligent and has been opened out for "anyone who's trying to reach people on mobile no matter how big or small your company or idea is, or what problem you're trying to solve" (How To Build Bots for Messenger - Facebook for Developers, 2016). That gives the possibility to make an intelligence bot as an interface between a user (student) and a service (Moodle) (Nenkov et al., 2016). Simplified communication between a teacher and a student through the Facebook Messenger arranged by Artificial Intelligence powered chatbot on wit.ai technology with natural language processing (Fig. 1).

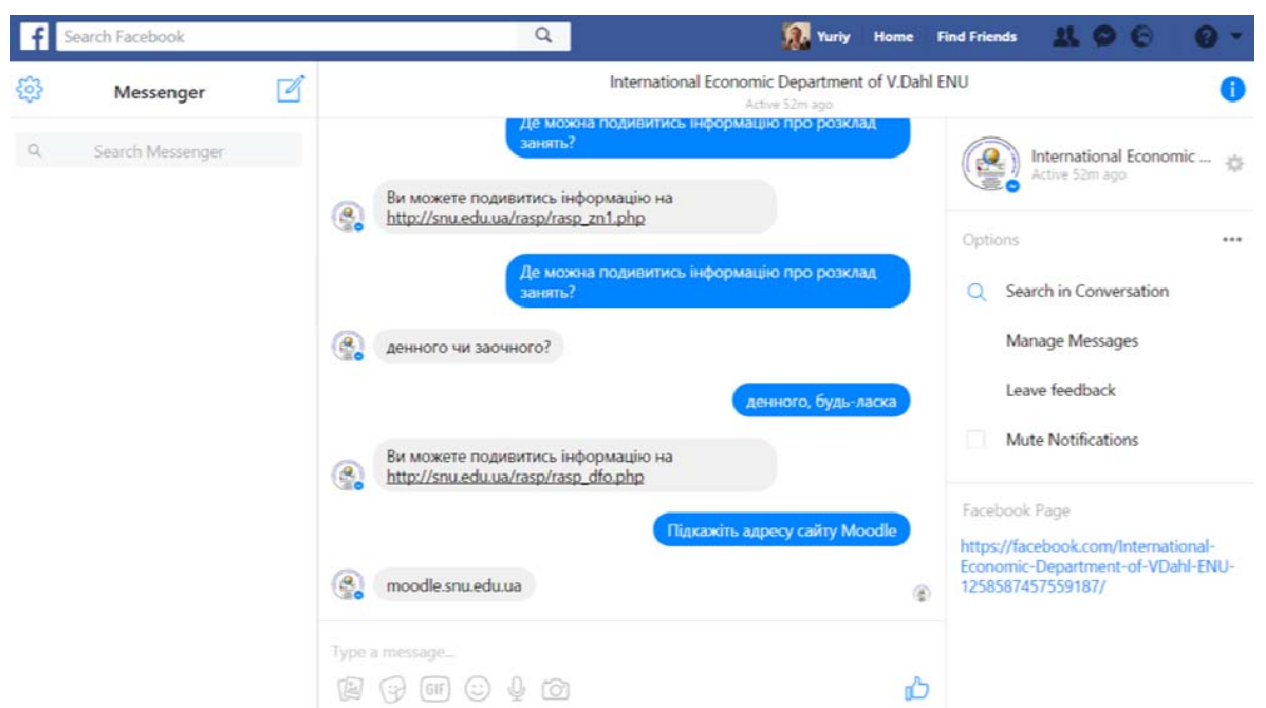

Fig. 1. Example of dialogue with Artificial Intelligence powered Facebook Messenger Bot.

\section{Outcomes}

While considering distance learning in education, cognitive technologies for Human Resource development and artificial technologies in education we focus on methodology in language teaching and distance learning. The greatest advantage of the intelligent and cognitive technologies is the ability to provide an individual approach to students given the opportunity to learn the language at an individual pace and sequence that takes into account the psychological characteristics of each student, which greatly improves the quality of mastering linguistic material. As approach to foresee future changes at workplace we propose upgraded curricula with emphasis on intelligent and cognitive technologies.

\section{Implications}

The use of intelligent systems allows the automation of student-teacher 
communication due to providing the interaction between a teacher, a student and an educational institution. The proposed variant of the architecture of such a system used Facebook platform with Artificial Intelligence powered wit.ai chatbot. For the students this enables to integrate learning in familiar for student social network environment. As for the teachers this enables to reduce the burden and to relieve them from monotonous work. The educational institution will be able to organize the learning in a more flexible way. Also the proposed approach could be one of the first step towards machine teaching. Transition from discrete paradigm of information processing (programming for Turing machines) to continuous paradigm (learning of artificial intelligence) allows faster and more accurate adaptation to environmental requirements. In future it can yield the most suitable solution for knowledge transfer from one agent to another in order to ensure inclusive and equitable quality education.

\section{Acknowledgments}

The publishing of this article was possible thanks to the support of the "Konstantin Preslavsky" University of Shumen (Bulgaria) and its research project: RD-08122/06.02.17 „Models and applications of deep machine learning in intelligent systems“.

\section{References}

Artificial Intelligence Enables Proficiency (2017, Feb 21).

Bausch, K. (2001). The Emerging Consensus in Social Systems Theory. New York: Kluwer Academic.

Bondarenko, G. (2014). Formation of professional communicative competence of economics students by means of distance education. In Proceedings of 12th International Conference Open Learning and Distance Education. Riga, Latvia.

Buzko, I.R., Dyachenko, Y.Y. (2012). Formation of methodological grounds for staff development. Actual Problems of Economics, 3, 8-12.

Crawford, C.S. (2005). Actor Network Theory. In Ritzer G. (Ed.) Encyclopedia of Social Theory (pp. 1-4). Thousand Oaks: SAGE Publications.

Dyachenko, Yu. (2010). Methodology of Personnel Development in the Frames of Economic Paradigms. Information Technologies, Management and Society, 3(2), 96-97.

How To Build Bots for Messenger - Facebook for Developers (2016). Retrieved from https://developers.facebook.com/blog/post/2016/04/12/bots-for-messenger/

Latour, B. (2005). Reassembling the Social. An Introduction to Actor-Network-Theory. Oxford: Oxford University Press.

Law, J. (2009). Actor-network theory and material semiotics. In B.S. Turner (Ed.), The New Blackwell Companion to Social Theory (pp. 114-158). Oxford: Wiley-Blackwell.

LeCun, Y. (2017, Jan 10). Predicting under Uncertainty: the Next Frontier in AI, EPSRC CDT. Data Science Distinguished Lecture. Edinburgh.

Luhmann, N. (1992, Feb.). The Concept of Society. Thesis Eleven, 31, 67-80.

Luhmann, N. (1995). Social Systems. Stanford University Press: Stanford.

Marcus, D. (2016). Messenger Platform at F8. Retrieved from http://newsroom.fb.com/news/2016/04 /messenger-platform-at-f8/

Nenkov, N., Dimitrov, G., Dyachenko, Y.Y. \& Koeva K. (2016). Artificial intelligence technologies for personnel learning management systems. 2016 IEEE 8th International Conference on Intelligent Systems, IS 2016 - Proceedings, 189-195.

Nenkov, N. (2015). Implementation of a course in "Artificial Intelligence and Expert Systems" on top of a distance-learning platform. Computer Modelling \& New Technologies, 19(4C), 34-36.

Parsons, T. \& Shils, E. (1951). Toward a General Theory of Action. Cambridge: Harvard University Press. 
Petrova M. \& Petrov O. (2002). Practice, problems and perspectives of distance learning. Internet-EducationScience, 1, 106-108.

Petrova, M. (2007). Distance Learning - changing the world of education. III International scientifically-practical conference "Actual problems of modern sciences". Dnepropetrovsk.

Pustovit, V., Goroshkina, O. \& Mel'nyk, T. (2013). The theory and practice of teaching philological subjects in high school. Lugansk: Globus. Retrieved from https://chatbotslife.com/artificial-intelligence-enablesproficiency-44150873011c\#.etbom01 mm

UN [United Nations] (2015). Transforming our world: the 2030 Agenda for Sustainable Development. Resolution adopted by the General Assembly on 25 September 2015. A/RES/70/1. Retrieved from: https://sustainabledevelopment.un.org/post2015/transformingourworld (28 September 2016).

Zuckerberg, M. (2017, Feb 16). Building Global Community. Retrieved from https://www.facebook.com /notes/mark-zuckerberg/building-global-community/10154544292806634. 